This item was submitted to Loughborough's Research Repository by the author.

Items in Figshare are protected by copyright, with all rights reserved, unless otherwise indicated.

\title{
Process plant safety information repository and support for safety
}

\section{applications}

PLEASE CITE THE PUBLISHED VERSION

http://dx.doi.org/10.1016/j.jp.2012.04.004

PUBLISHER

(C) Elsevier

VERSION

AM (Accepted Manuscript)

LICENCE

CC BY-NC-ND 4.0

REPOSITORY RECORD

Chung, Paul Wai Hing, J. de Brugha, Joe McDonald, and Jim Madden. 2019. "Process Plant Safety Information Repository and Support for Safety Applications". figshare. https://hdl.handle.net/2134/10578. 
This item was submitted to Loughborough's Institutional Repository (https://dspace.lboro.ac.uk/) by the author and is made available under the following Creative Commons Licence conditions.

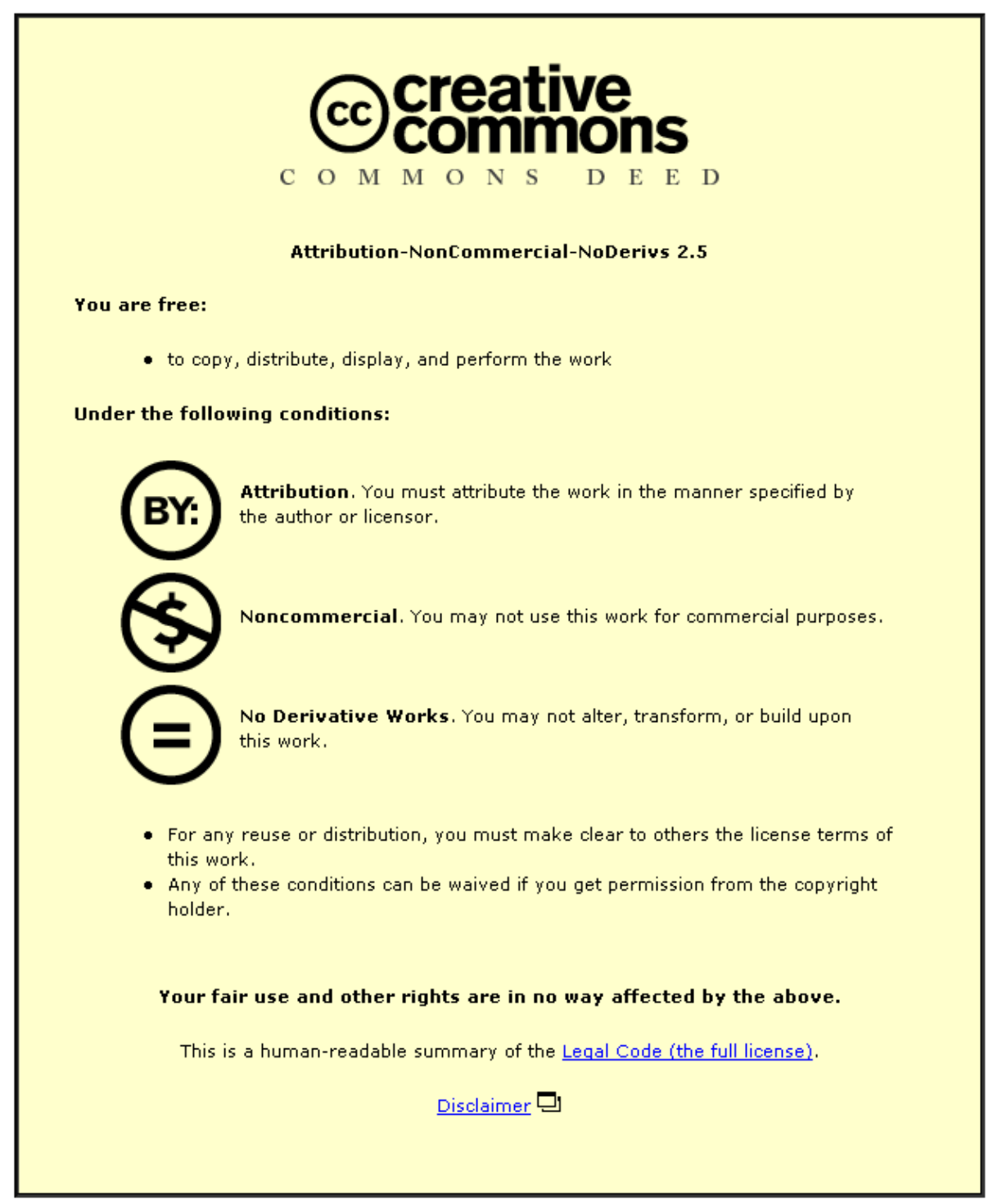

For the full text of this licence, please go to: http://creativecommons.org/licenses/by-nc-nd/2.5/ 
Process Plant Safety Information Repository and Support for Safety Applications

P.W.H. Chung ${ }^{1}$, J. de Brugha ${ }^{2}$, J McDonald ${ }^{2}$ and J. Madden ${ }^{2}$

\author{
Department of Computer Science ${ }^{1}$ \\ Loughborough University \\ Leicestershire \\ England, UK, LE11 3TU \\ p.w.h.chung@lboro.ac.uk

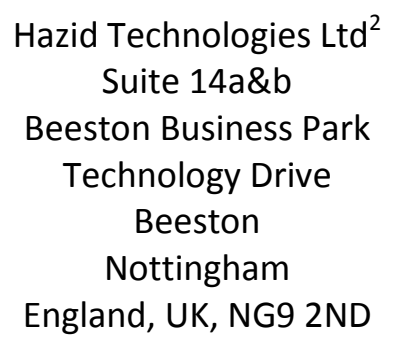

Abstract

The consideration of safety of processing plants from design to operation involves many tasks. Different techniques and tools have been developed to assist in carry out those tasks. With the advances in computing technologies, both in hardware and software, there is the opportunity to bring together the vast amount of engineering, hazard and risk data and handle them in an efficient way to manage and improve safety throughout the life time of a plant. This paper proposes keeping such data in a process plant safety information repository which can be easily accessed by different safety related tool to enhance the efficiency of safety identification and analysis tasks.

\title{
1. Introduction
}

Kletz $(1993 ; 1994 ; 1998)$ has been a strong advocate of learning from the past in order to maintain and improve safety. He has also been a key contributor to the idea of integrating safety application tools with computer-aided design (CAD) systems. Examples considered are integrating accident databases with CAD systems and with electronic permit-to-work systems so that safety related information is provided in a timely manner thus increasing its effectiveness (Iliffe et al 1999; lliffe et al 2000).

This paper expands on this theme and describes a novel approach to integrated safety analysis and information management which can be a basis to meet the demand for a comprehensive integrated process safety management system as recommended by the Baker Report (Baker et al, 2007). With a process plant safety information repository, both archival and most-up-to-date information could be easily accessed to deal with the problem at hand. The remainder of the paper is organised into five sections discussing the general idea of safety information repository, the safety applications that can be built on top of the repository, the implementation of the idea in a commercial system, application examples and the conclusions. 


\section{Safety Information Repository}

With the advances in internet and database technologies, we advocate the creation of safety information repositories for process plants where all the engineering, hazard and safety data are stored so that they can be accessed by any subsequent tasks that require them in a convenient manner for processing without additional effort or cost. This will help to remove the boundary that exists between different groups of people working on the same process plant.

The concept of process safety information repository is illustrated in figure 1. As different types of safety-related studies are carried out the information generated is stored in a single repository where it can be viewed by people from different geographical locations so that it is available to them in the format that they need it and when they need it. It is important to note that the plant safety information repository is not just a collection of documents and spreadsheets stored on a shared drive accessible on the internet. The repository is a structured database where the fields are clearly specified and the data can be linked and searched. Engineers, safety experts and plant operators collaborate on the same up-to-date information, instead of communicating by passing around documents and files, thus removing double data entry and silos between work processes.

The information in the repository must be kept consistent with plant modifications to ensure that the safety information used by plant operators and managers is reliable and up-to-date. This is achieved by automatically capturing the plant design model and information held on the P\&ID and converting them into a safety model upon which the safety analyses are based. The approach joins various safety related tasks - Plant and P\&ID modifications, P\&ID Review, hazard studies, SIL/LOPA, and action tracking and resolution - with the mainstream engineering work processes through data exchange with an intelligent P\&ID system. This also enables the consideration of the impact of design decisions on safety earlier and throughout the plant lifecycle.

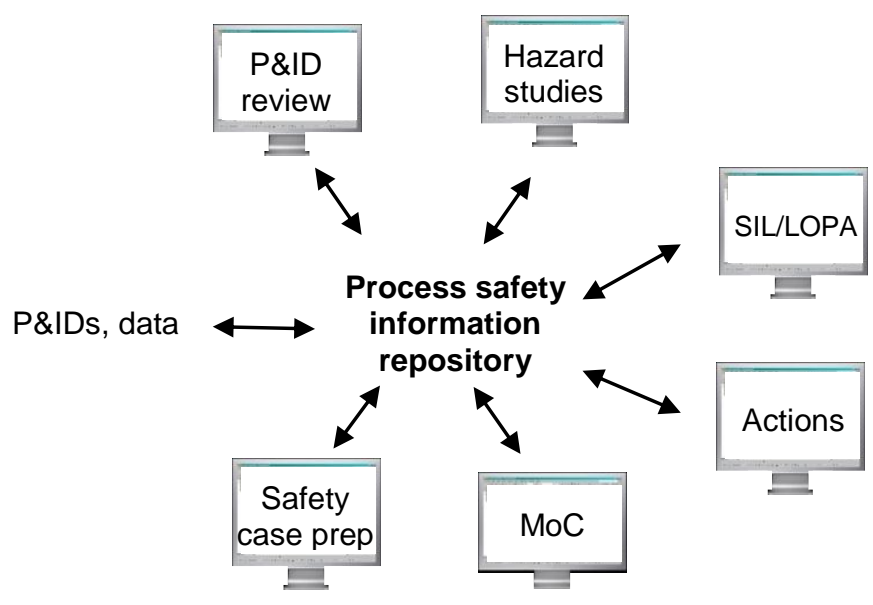

Figure 1 Process plant safety information repository to support safety applications

\section{Support for Safety Applications}

In addition to accident databases and permit-to-work systems already mentioned, different safetyrelated applications can be built on top of the information repository, as shown in figure 1, thus making use of, and contributing to, the information repository. This section explains the principles and fundamentals of these applications and how they work together to support the engineering process. 
With seamless access to engineering and safety-related data, organisational and geographical boundaries are reduced, and with the safety application support companies can, therefore, raise the bar on process safety performance by:

- increasing quality and efficiency, and reducing late changes;

- demonstrating compliance with engineering standards and guidelines;

- assimilating safety knowledge and reuse across projects.

\subsection{P\&ID Review}

First, at any stage in P\&ID development the drawings need to be checked against engineering standards and guidelines to ensure that best practices and preferred configurations are followed. A P\&ID checker that embodies the rules specified in the standards and guidelines and automatically checks for non-compliance would reduce the number of checking and rework cycles between process engineer and designer. This provides a means of demonstrating and documenting compliance and will result in fewer late changes and make the formal design reviews and Hazop studies more efficient with less actions resulting.

The design rules can be very varied covering things like pipe sizes, valve configurations and drawing conventions. Here are some sample rules:

- no butterfly valves on piping < 3 inches;

- insulation on all piping over $140^{\circ} \mathrm{F}$ operating;

- all pumps, compressors, and heat exchangers shall have inlet and outlet isolation valves;

- no pipe size over 2 inches if flow is < 80 GPM;

- all lines should have low point drains;

- bleed valves will be installed on the inlet and outlet of relief valves between the isolating valves;

- fail position should be shown for all automated valves;

- the control valve is at least one size smaller than the line;

- an overflow line or a gooseneck on a tank is at least one size larger than the suction line into the tank;

- there must be no isolation valve between a pressure vessel and its pressure relief valve

- the pressure relief valve set pressure must be less than the maximum allowable pressure of the protected vessel.

The rules can be programmed so that they can be checked against the electronic P\&ID and engineering data automatically to report any non-compliance if found. The report can then be reviewed. As rules do not replace experienced engineering judgment (Black et al, 2007; Hale 1990) engineers can override guidelines but must document a reason. The reviewed report can then be stored in the safety information repository. If the review resulted in changes to the P\&IDs then the process could be iterated until the engineering integrity of the P\&IDs was confirmed.

\subsection{Hazard and Operability Studies (HAZOP) and SIL/LOPA Determination} HAZOP (Kletz, 1999) are widely used in the process industry for identifying hazard and operability problems in process plants. However, HAZOP is a very people-intensive process. The safety information repository approach offers help in three different ways. The first as already mentioned is to ensure that the P\&IDs are properly prepared and meets a certain required standard. This would remove some of the unnecessary time spent on identifying them in HAZOP meeting and prevent late changes. The second is in HAZOP meeting preparation. With the electronic version of the P\&IDs and codified knowledge of HAZOP, tailored HAZOPs forms can be generated line by line for specified sections as expected in HAZOP meetings. Third, with codified knowledge of component failures and fault propagation captured from plant experience, some of the routine fault consequence scenarios 
can be automatically generated and part of the form completed (Suzuki, et al, 1997; McCoy, et al, 1999; Zhao, et al, 2005). This would allow the HAZOP team time to focus on creative thinking and exploring less obvious fault consequence scenarios.

Some cause-consequence scenarios identified from a HAZOP would require SIL/LOPA determination to assess their severity. This information could be entered and directly linked to the HAZOP report. The advantage is that the HAZOP report could be filtered to display consequences above a selected level of severity.

\subsection{Action and Change Management}

Actions would result from P\&ID review and HAZOP studies. They need to be followed up and managed in a systematic way to ensure proper closure. In the repository, actions can be linked directly to a P\&ID review and a HAZOP report. Emails could be sent to engineers to inform them of their actions automatically and they could access the reports directly and update the status of the actions. Automatic status checks could be carried out so that reminders could be sent if necessary. The system can maintain a complete history of each action through to close out. Information about when and why an action was initiated, and when and what was done about it can be easily found and traced. In addition to action management, review of changes is supported by the other tools already mentioned, e.g. reviewing a P\&ID after it has been changed.

\subsection{Safety cases}

The safety information repository provides an audit trail of essential and critical activities, and the information generated. The information can be used to demonstrate compliance and help in the preparation of safety cases (HSE, 2005) thus saving a lot of cost of effort in collating information from different sources and geographical locations. With the safety information repository, relevant information can be extracted for preparation for safety cases. Furthermore, with appropriate report templates the information could be automatically structured and filled sections of a safety case.

\section{Smart Plant Process Safety}

The approach outlined above is implemented by HAZID Technologies (HAZID, 2012) in partnership with Loughborough University and Intergraph Corporation and integrated with SmartPlant ${ }^{\circledR}$ P\&ID (Integraph, 2012). The overall system is known as Smart Plant Process Safety (SPPS). The safety information repository and the safety applications are linked to Intergraph's SmartPlant ${ }^{\circledR}$ P\&ID so that drawings and data are directly accessible to SPPS (see figure 2).

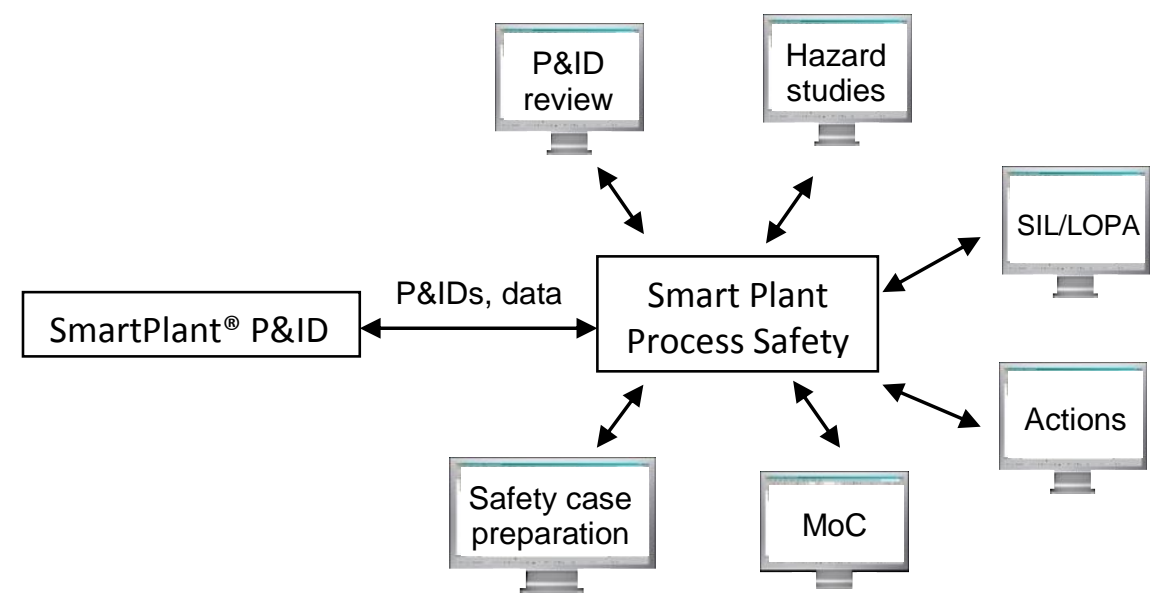

Figure 2 Smart Plant Process Safety (SPPS) 
SPPS has a number of modules which support the safety applications as shown in figure 2 . The P\&ID Review module (McDonald et al, 2009) has a rule building interface for engineers to add checks and for managers to validate them. Using the interface, around 3000 checks derived from ISO10418 (ISO, 2003) were built and tested in four person-weeks. Once built, the rules can be used to check any P\&IDs in minutes. SPPS also has a HAZOP module based on previous research (McCoy, et al, 1999). The module has a library of fault propagation models of equipments commonly found in process plants. SIL/LOPA assessment is linked in with the HAZOP module for assessing fault consequence scenarios. Action tracking is also linked in with the HAZOP module for following up any actions resulted from HAZOP meetings.

\section{Example Applications}

SPPS undergoes a large number of internal tests. Many successful trials have also been conducted with engineering and operating companies which covered different sectors:

- oil and gas development and refining

- oil and gas offshore

- oil tar sands

- general chemicals

- nuclear

- pharmaceuticals (continuous and batch)

Two applications of SPPS are described below to illustrate the functionalities and benefits of the P\&ID Review and HAZOP modules.

\subsection{P\&ID Review}

A trial was carried out with an engineering company with diverse projects and multiple drawing offices in different parts of the world. The aim is to assess whether the P\&ID review module could be adapted to allow a company like theirs to check all the P\&IDs that they received from the different drawing offices for compliance, not only with international standards but with their own internal drawing protocols. Six P\&IDs and associated data in SmartPlant ${ }^{\circledR}$ format were provided to test the system. In addition to the library of rules based on ISO 10418, 120 new rules were created to match the company's own guidelines. All the checks were applied to the six P\&IDs and the results were produced in 10 minutes and 20 seconds on a desktop PC. The results were reviewed. The problems picked up by the system matched what the company was expecting. Furthermore, the automated checks also reviewed some drawing inconsistencies on their reference P\&IDs.

When all the checks are completed, the system displays which checks are passed and which are failed. Part of the display is shown in figure 3. By selecting any of the rows the details of the check is given. For example, selecting the failed PSV Check on figure 3 gives the details shown on figure 4 . The rule that is responsible for the check is shown in figure 5 . It states that the set pressure for a pressure release valve should be less than or equal to the equipment it is protecting. In this case the set pressure for PSV-100 is 55 bar but the max operating pressure for the equipment it is protecting is 50 bar. The corresponding part of the P\&ID which failed the check is shown in figure 6 . For the same example, another rule also picked up the problem that there should be no obstructing valves in the pressure relief line. 


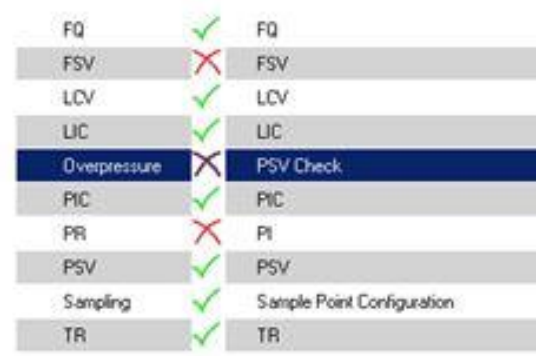

Figure 3 Screen displaying the results of design checks

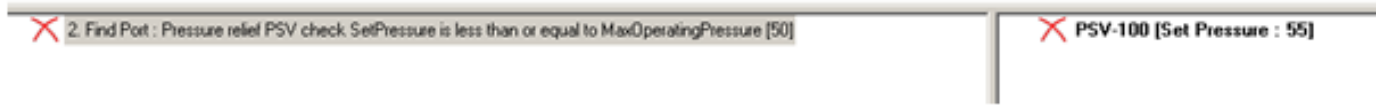

Figure 4 Details of a failed check

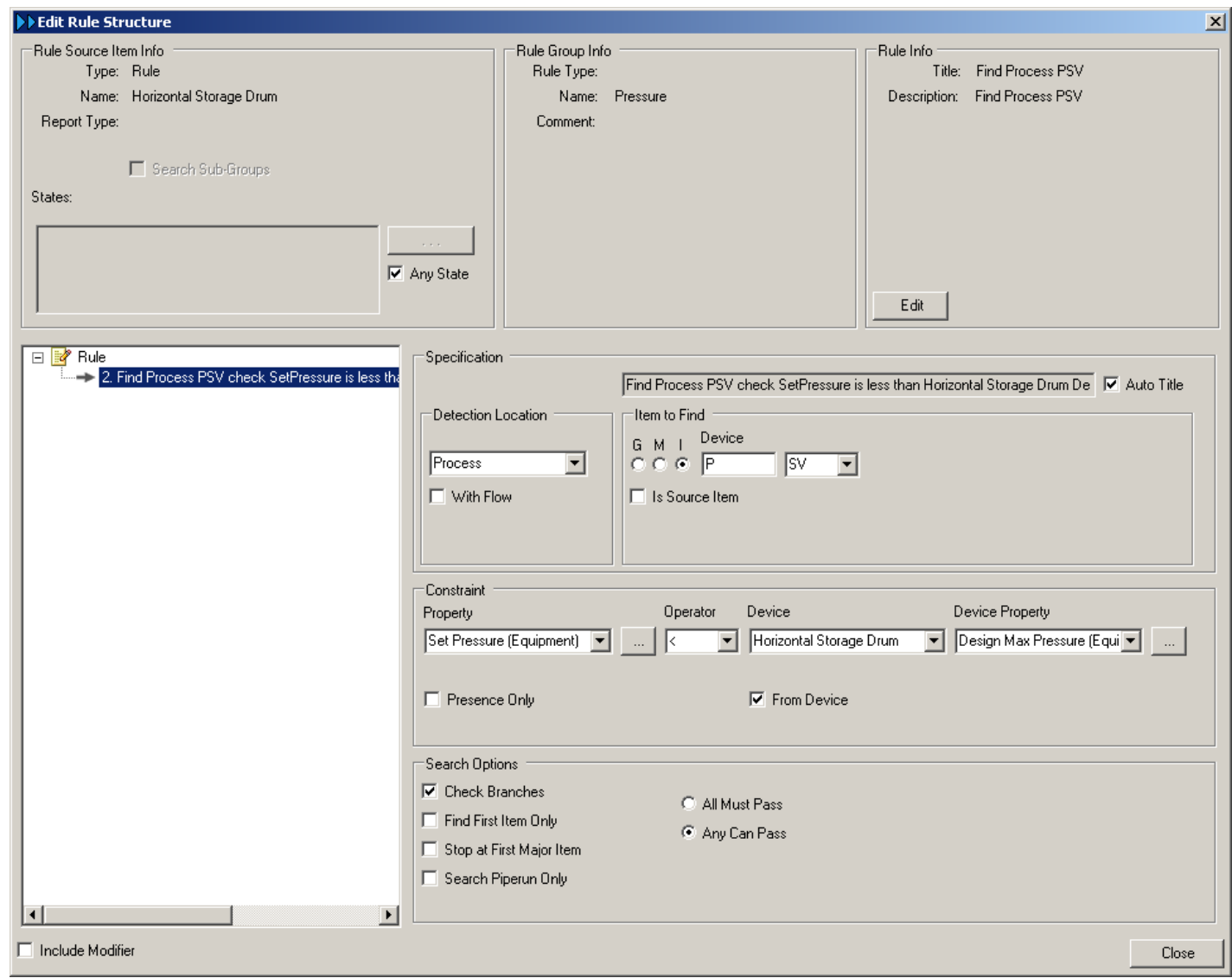

Figure 5 Details of the PSV checking rule 


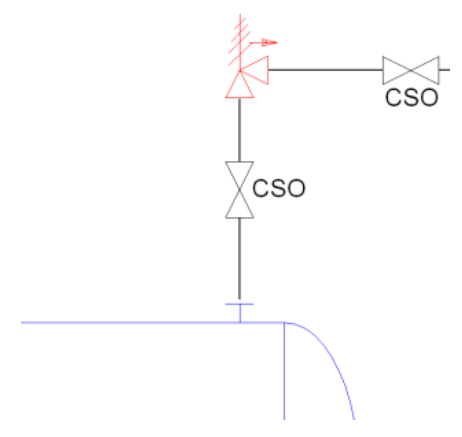

Figure 6 The part of the plant that failed a check

An example of a rule that has passed is a configuration rule that checks that a vessel should have a sampling point that can be used when its associated pump is running and there is no fluid feeding forwards (see figure 7). Figure 8 shows the part of the plant that has passed this particular check.

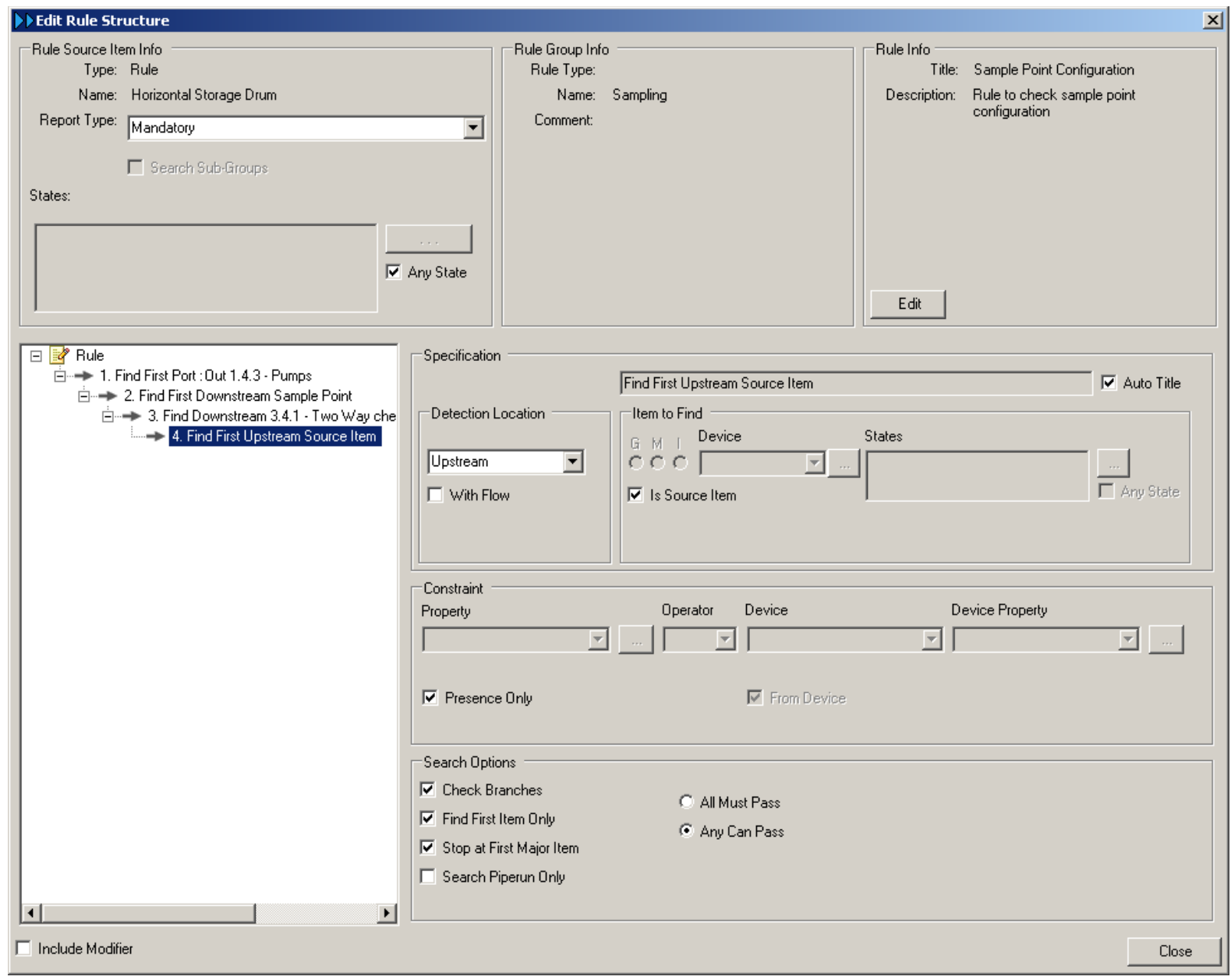

Figure 7 Sampling configuration rule 


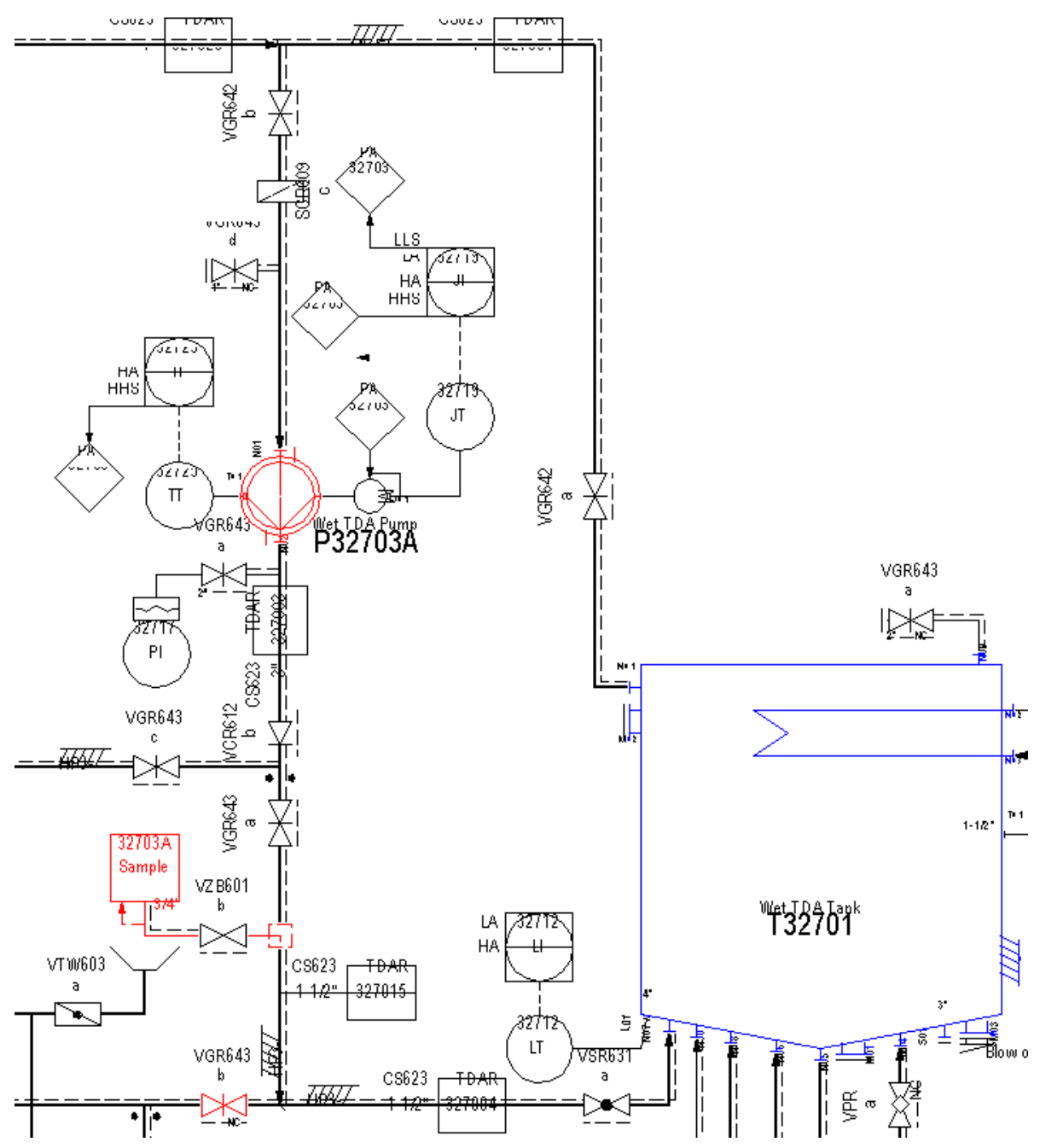

Figure 8 Sampling configuration that passed

The company agreed that the results generated by the P\&ID Review module were valid, and that real cost savings could be made because of the reduction of time engineers required to spend checking that drawings were correct. They also believe that there are benefits with management of change as drawings could be easily checked when they are modified. This will also bring benefits to HAZOP when the quality of drawings is ensured.

To illustrate the HAZOP module, the P\&ID of the hydrocarbon plant as published in Lawley (1974) is used here (figure 9) instead of using P\&IDs that are commercially sensitive provided by any of the companies. The hydrocarbon plant consists of a pair of pumps feeding a blanketed gravity separation unit with wet hexane. The water is collected in the boot of the separator and is periodically drained off manually by an operator; the dry hexane is pumped out of the separator and through a heat exchanger before leaving the P\&ID for further processing. The HAZOP module contains models of all the equipment present in the plant, comprising of 30 simple models of common components like piping components, instrumentation etc, and 3 more complex models the separator, the pumps (all of the same type) and the heat exchanger. 


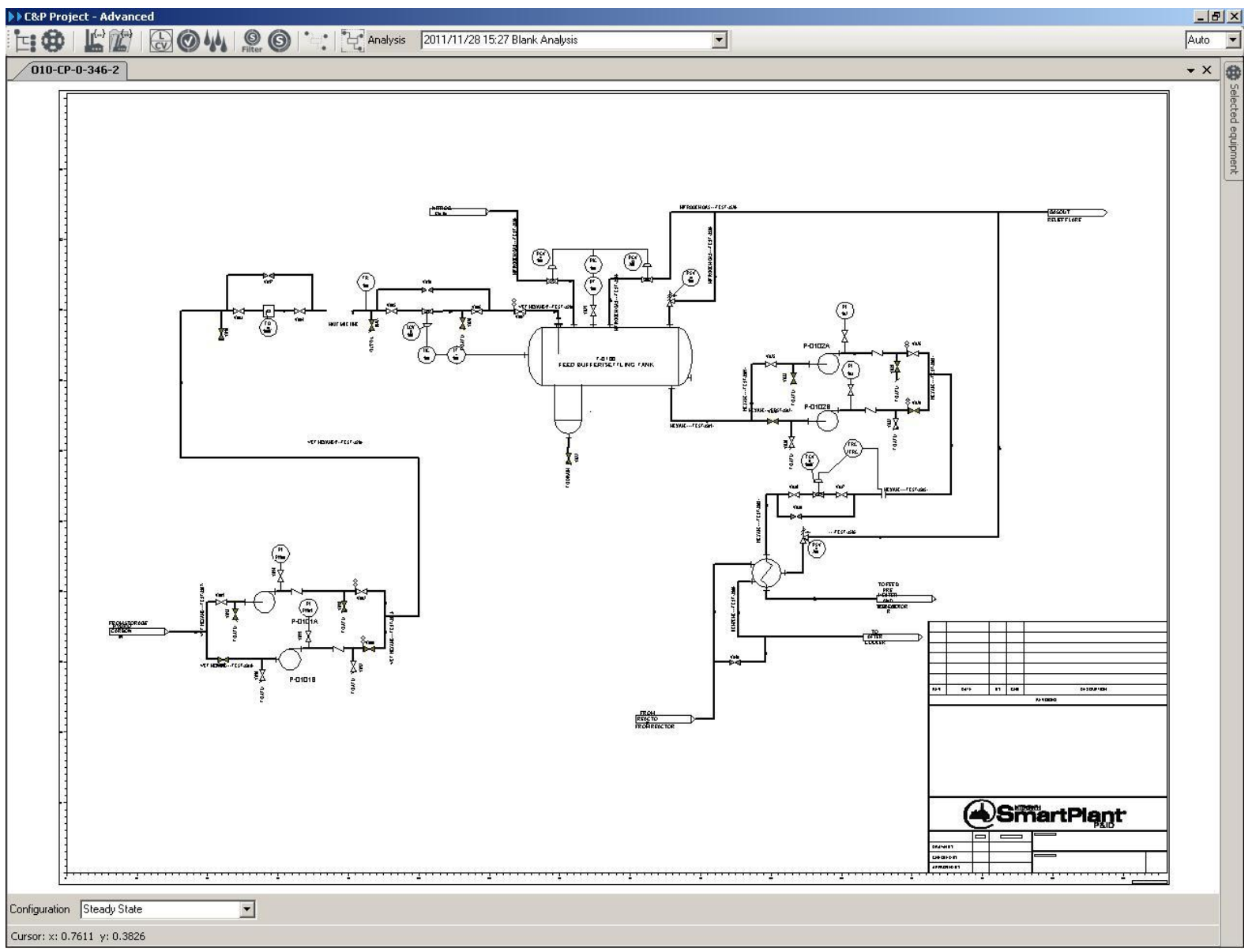

Figure 9 Hydrocarbon Plant (Lawley, 1994) as drawn in SmartPlant and displayed by SPPS

SPPS was used to node the P\&ID electronically, in order to best filter the information for the study team, three nodes were created as shown in figures 10 to 12 . 


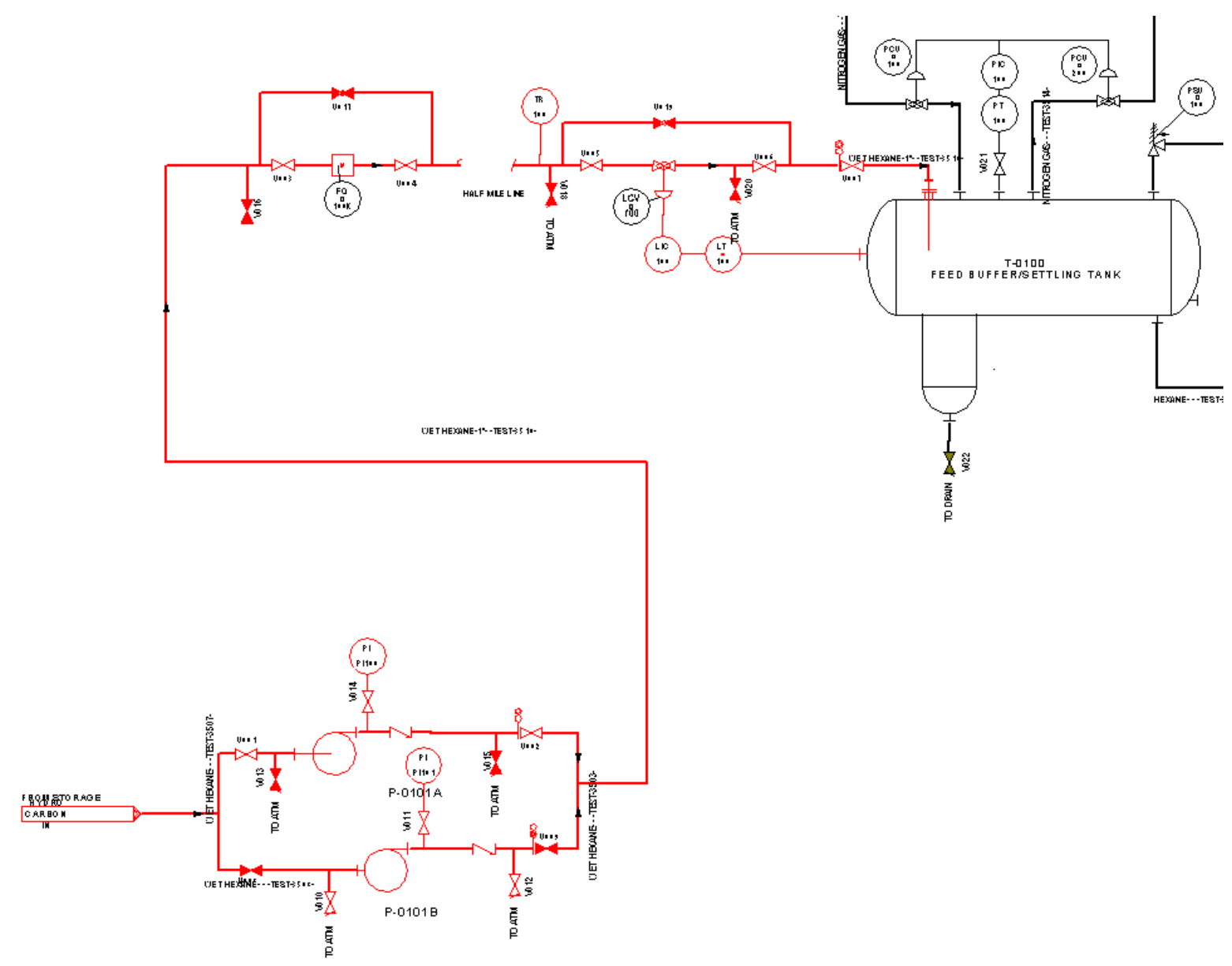

Figure 10 Node 1 (highlighted in red), as shown in HAZID

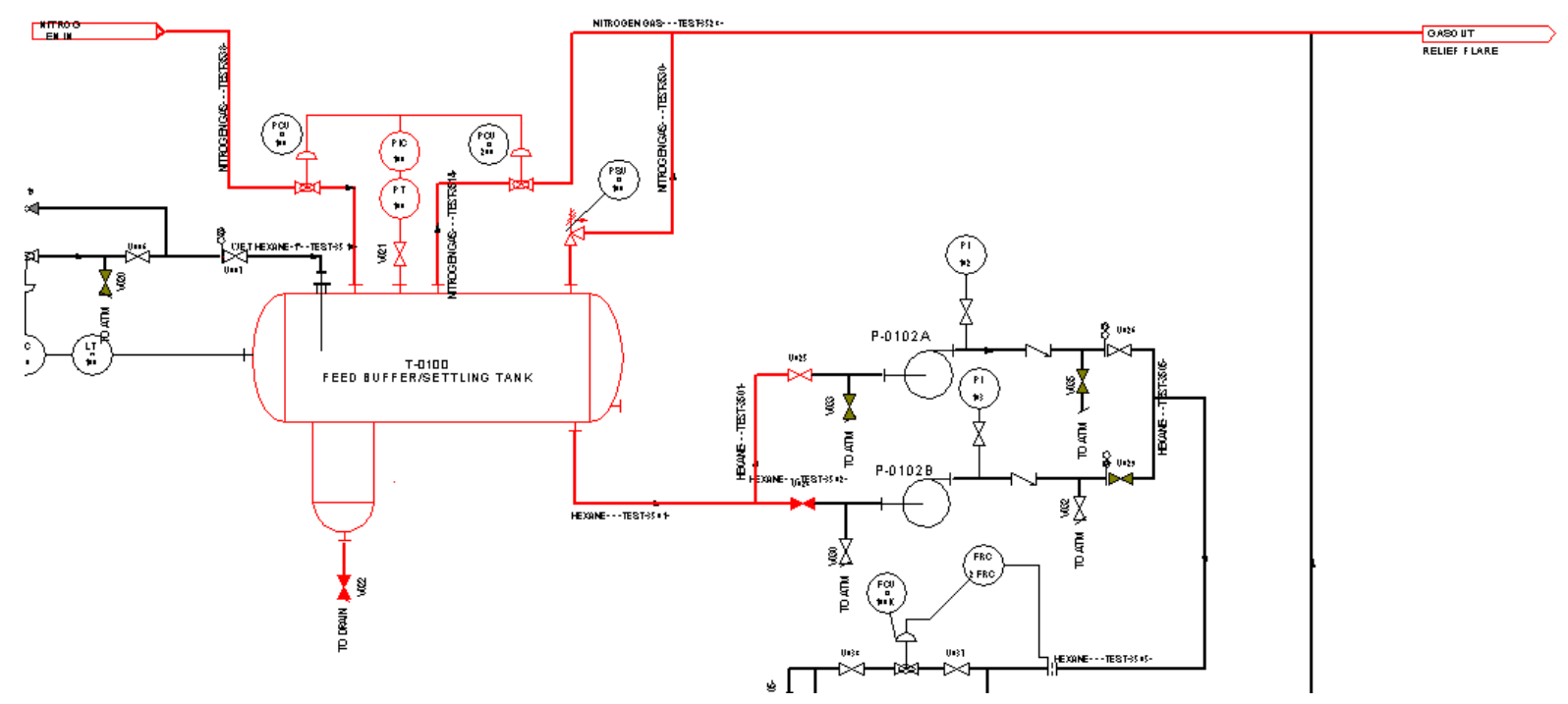

Figure 11 Node 2 (highlighted in red) 


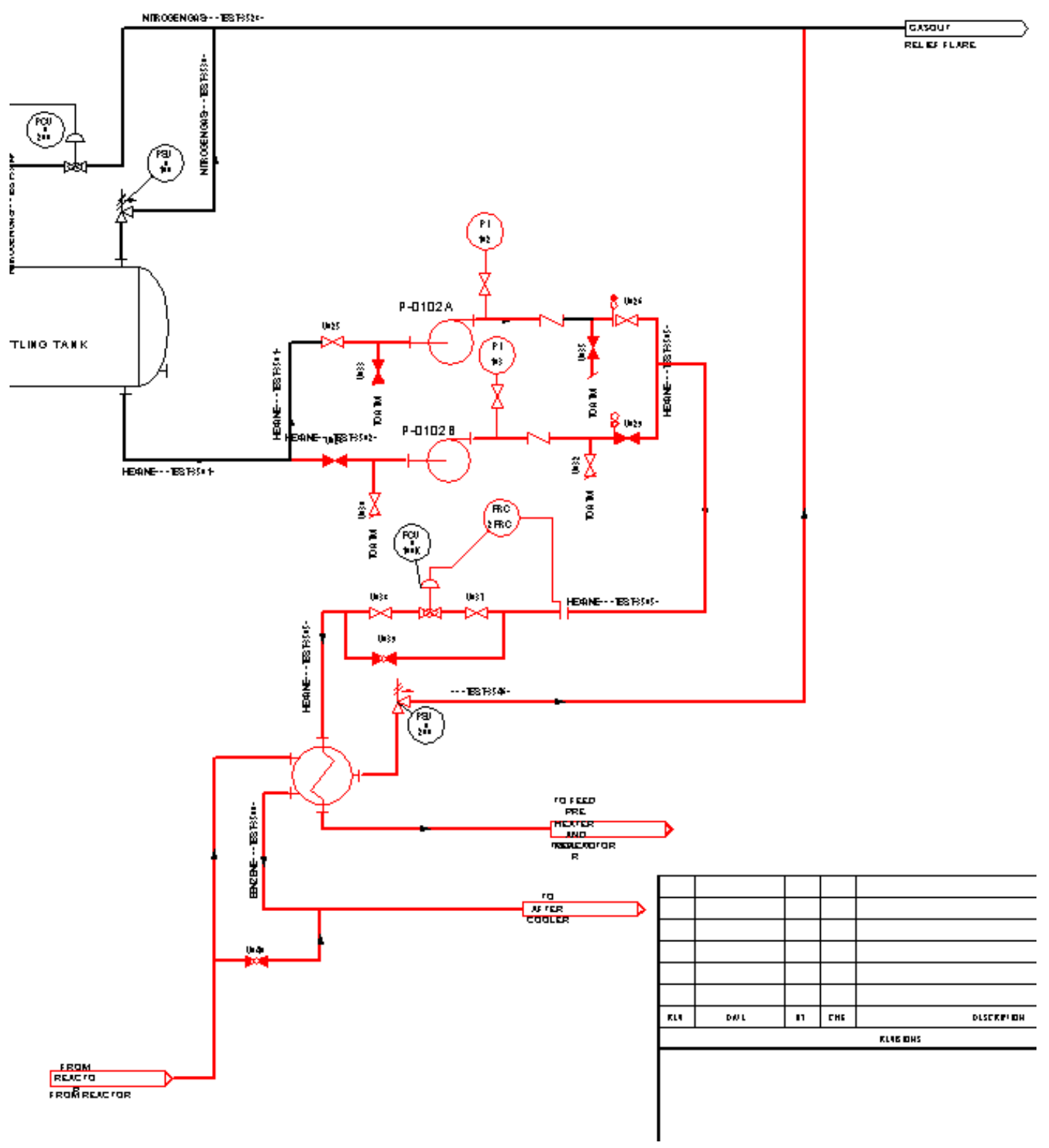

Figure 12 Node 3 (highlighted in red)

The plant was configured to match the operating conditions outlined in the original paper, and then run. The single P\&ID took 56 seconds for the system to analyse, filter and store the results. The system found 165 credible scenarios and they were reduced to 50 scenarios when the grouping algorithm was applied to group similar scenarios so that they could be studied as one scenario by the HAZOP team. Upon reviewing the results, it was found that HAZID had correctly matched all of the scenarios reported in the paper (Lawley, 1974) and had located additional credible scenarios due to the rigorous and exhaustive nature of computer-based hazard identification.

The hydrocarbon plant was then modified with a kickback added to the lines after the separator outlet pumps in order to protect the pumps from low level situations occurring in the separator (see figure 13). After the change was made, the HAZOP module was rerun to analyze the modified P\&ID. The results of the original and the modified plants were compared automatically by the HAZOP module to identify the effects of the change has on the plant. 
The comparison report highlights that the kickback removed the scenarios where the pump was potentially damaged by low level caused by upstream process disruptions, however the system correctly identified that the positioning of the kickback lines (downstream of the check valves) allowed for potential back flow from the heat exchanger to the separator in some No Flow situations (see figure 14). This illustrates that the comparison of change feature is useful for the management of change.

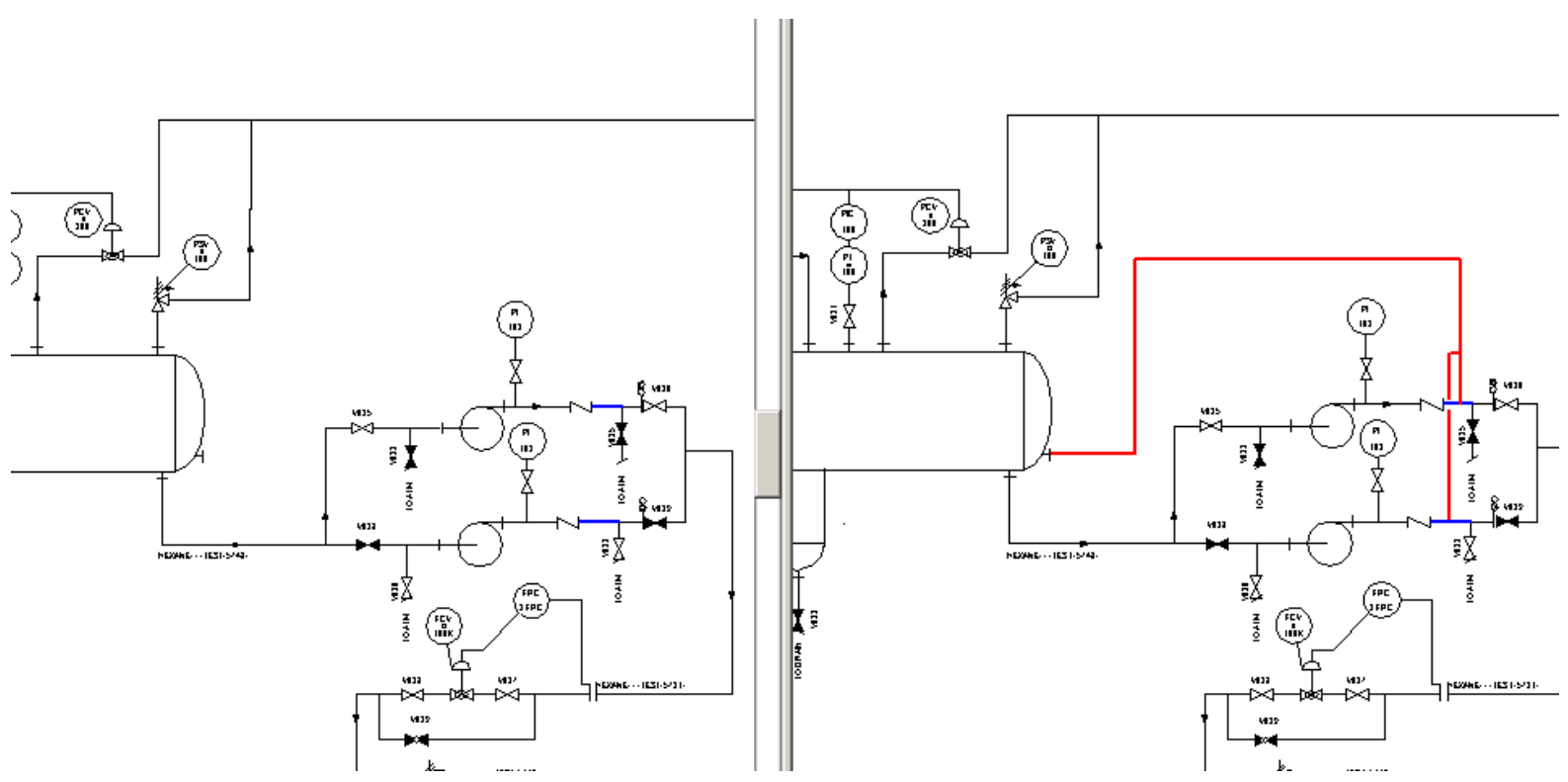

Figure 13 Part of the hydrocarbon plant (left) and the same part with kickback line added (right)

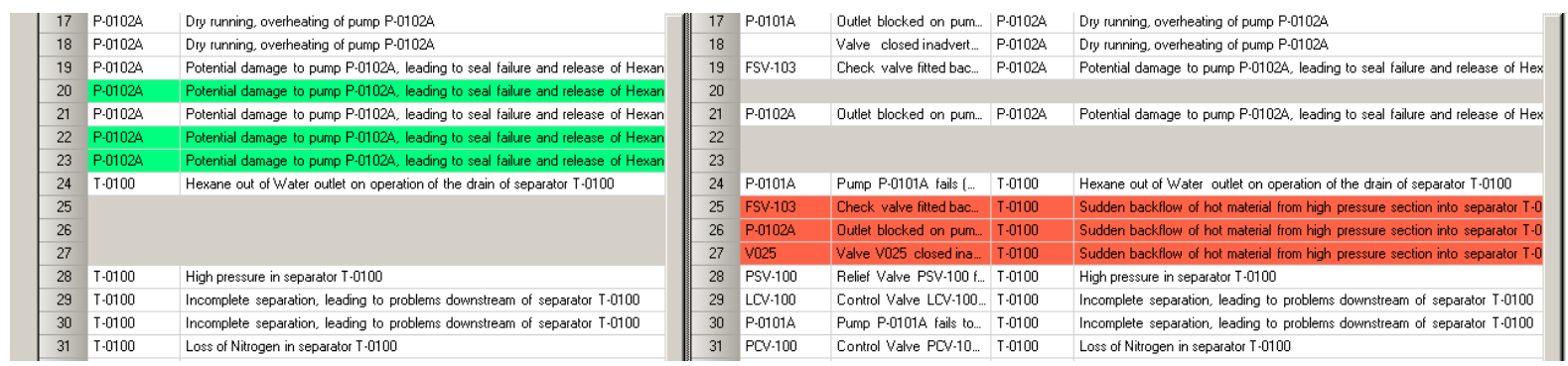

Figure 14 Comparison report showing that some scenarios no longer occur in the changed drawing (green) but that there are some new scenarios that the change has introduced (red)

A company that was involved in a larger trail that applied the HAZOP module to their own P\&IDs agreed that the results generated by the module were valid. Benefits noted by the company include:

- $50 \%$ Time saving over traditional methods

- Use of the system allows staff to focus on quality as mundane aspect is eliminated as highly competent staff can focus on unusual scenarios.

- Data retention and evolution of data over time thus supporting change control

- Data available at click of a button

- Extensive reporting capabilities thus supporting document preparation.

6. Summary and conclusions 
Plant engineering and operations generate vast amount of information and data. The advances in database and internet technologies enable the development of safety information repository that provides an archive and easy access to the information. One of the most significant advantages of having such a repository is realised when different safety-related tools are interfaced to access, and contribute to, the repository. Therefore, duplication of data entry is removed and up-to-date and consistent data is always available; checks on data and drawing integrity can be carried out automatically; actions that followed from safety considerations can be tracked and traced.

A wide range of safety-related applications can be developed on top of the safety information repository. The two examples outlined in the paper illustrate the different benefits that such an integrated approach brings.

\section{References}

Baker III, J.A., Bowman, F.L., Erwin, G., Gorton, S., Hendershot, D., Leveson, N., Priest, S., Rosenthal, I. Tebo, P.V., Wiegmann, D.A. \& Wilson, L.D. (2007), The Report of the BP U.S. Refineries Independent Safety Review Panel . (available on the website www.bp.com)

Black, J., Hopper, M. and Smith, H. (2007), Making a Success of Principles-based Regulation, Law and Financial Markets Review, May 2007, pp191-206.

Hale, A.R. (1990), Safety Rules O.K.? Possibilities and Limitations of Behaviural Safety Strategies, Journal of Occupational Accidents, Vol(12), pp3-20.

HAZID (2012), http://www.hazid.com/

HSE (2006), A Guide to the Offshore Installations (Safety Case) Regulations 2005 ( $3^{\text {rd }}$ Edition), HSE.

ISO (2003), ISO10418: Petroleum and natural gas industries - Offshore production installations Analysis, design, installation and testing of basic surface process safety systems.

Iliffe, R.E., Chung, P.W. and Kletz, T.A. (1999) More Effective Permit-to-Work Systems, Transactions of the IChemE, Part B, 77(March), pp 69-76.

Iliffe, R.E., Chung, P.W., Kletz, T.A. and Preston, M. (2000), The Application of Active Databases to the Problems of Human Error in Industry, Journal of Loss Prevention in the Process Industries, 13(1), pp 19-26.

Intergraph (2012) http://www.intergraph.com/products/ppm/smartplant/pid/default.aspx

Kletz, T. (1993), Lessons from Disaster, IChemE.

Kletz, T. (1994), Learning from Accidents ( $2^{\text {nd }}$ Edition), Butterworth Heinemann.

Kletz, T. (1998), What Went Wrong - Case Histories of Process Plant Disasters, Gulf Publishing Company.

Kletz, T. (1999), HAZOP \& HAZAN (4 ${ }^{\text {th }}$ Edition), IChemE.

Lawley, H.G. (1974), Operability Studies and Hazard Analysis, Chemical Engineering Progress, Vol. 70, Apr., pp. 45-56

McCoy, S.A., Wakeman, S.J., Larkin, F.D., Jefferson, M., Chung, P.W., Rushton, A.G., Lees, F.P. and Heino, P.M. (1999), HAZID, A Computer Aid for Hazard Identification 1. The STOPHAZ Package and the HAZID Code: An Overview, the Issues and the Structure, Transactions of the Institution of Chemical Engineers, Part B, 77(November), 1999, pp 317-327.

McDonald, J., Rieley, B., Madden, J., de Brugha, J. and Chung, P.W.H. (2009), A software system to check designs automatically against process safety and best practice, Proceedings of Hazard XXI, IChemE, Hazards XXI, Manchester, UK, 2009, pp.79-84.

Suzuki, K., Shimada, Y., Sayama, H. and Nojiri, I. (1997), Application of Knowledge Engineering to Automated HAZOP, Proceedings of ECCEI, Vol. 1, 1997, pp 787-790.

Zhao, C., Bhushan, M. And Venkatasubramanian (2005) PHASUITE: An Automated HAZOP Analysis Tool for Chemical Processes. Part II: Implementation and Case Study, Transaction of the Institution of Chemical Engineers, Part B, Vol 88, pp 533-548. 